\title{
A gestão do conhecimento no setor público: seus conceitos, modelos e ferramentas
}

\author{
Evandro José Bilycz de Camargo* \\ André da Silva Pereira***
}

\section{Resumo}

\begin{abstract}
A gestão do conhecimento, vista como forma processual, está junto das necessidades institucionais e organizacionais, formalizadas como modos de gestão. $\mathrm{O}$ objetivo deste trabalho é conceituar e apontar as melhores práticas de gestão do conhecimento junto ao setor público. Para isso, traz a abordagem de Nonaka e Takeuchi (1997), Davenport e Prusak (1998), Dixon (2000), dentre outros. É uma pesquisa bibliográfica, que procura identificar os meios para a administração pública alcançar uma capacidade mais orientada de abordagem gerencial e produtiva, inclusiva e concomitante.
\end{abstract}

Palavras-chave: Conhecimento. Gestão. Setor público.

* Administrador pela Universidade de Passo Fundo (UPF). E-mail: tecocamargo@via-rs.net

** Doutor em Economia Ufrgs, professor e pesquisador da Faculdade de Economia, Administração e Contabilidade da Universidade de Passo Fundo (UPF/RS). E-mail: andresp@upf.br 


\section{Introdução}

A existência de um comportamento institucionalizado, aliado aos fatores culturais, faz da sociedade brasileira um misto de ideais e complexidades. Os acontecimentos contemporâneos, identificados com a transparência e a eficiência, particularmente, aparecem como metas organizacionais importantes, que nem sempre são atendidos.

Destaca-se a maneira pela qual se entende uma instituição, em particular, aquela derivada do ambiente público. Em linhas gerais remete-se ao desafio do gestor: identificar o principal papel de uma gestão, que contemple o conhecimento na instituição pública. $\mathrm{O}$ que se considera relevante na contemporaneidade é o fato de o Estado ser uma máquina geradora de expectativas e perspectivas, fomentada por atores da sociedade, como a governança e os processos sociais, que geram uma visão de futuro, cuja finalidade é a (GUBERMAN, 2010).

Quando se observa o meio administrativo, alguns aspectos tendem a se destacar, como a informação, a comunicação, a inovação ou a organização. A importância da gestão do conhecimento se afirma como uma forma processual que atenta para as necessidades institucionais e organizacionais. Constata-se isso quando se define a gestão do conhecimento como um processo de identificação, maximização, codificação e compartilhamento do conhecimento, estrategicamente relevante para as organizações (TERRA, 2001).

Nonaka e Takeuchi (1997), por meio da teoria da criação do conhecimento, e Davenport e Prusak (1998), através da geração do conhecimento, apresentam dois momentos importantes ligados à gestão do conhecimento. A promoção, a idealização e/ou a implementação de processos organizacionais, em que a gestão e o conhecimento são vistos como elementares e fundamentais para a disseminação e o desenvolvimento de uma organização, aparecem como fontes de teorias e de pensamentos dos mais diversos segmentos.

Este é um artigo de revisão teórica, que se parte de uma pesquisa bibliográfica Seu objetivo é destacar as principais discussões teóricas ligadas às práticas de gestão do conhecimento no setor público. Para isso, foram abordados os estudos de Nonaka e Takeuchi (1997, 2008), Davenport e Prusak (1998), Wiig (2000, 2002), Terra (2001, 2012), Woodford (2003), Syed-Ikhsan e Rowland (2004), Monavvarian e Kasaei (2007), Abdullah e Date (2009), Salavati, Shafei e Shaghayegh (2010), Batista (2012); Campos (2013), Marcante et al. (2015), dentre outros. 


\section{A gestão do conhecimento}

A concepção de gestão do conhecimento (GC) aparece, junto à administração, como um importante fator de inovação e de mudanças. Ou, ainda, é comparada a uma "mola indutora", da qual questões como produtividade e criatividade dos colaboradores produzem conhecimento (TERRA, 2012). Em termos organizacionais, observa-se, a partir das premissas funcionais, uma tendência para o engajamento da empresa e de toda a sua percepção às pessoas e a seus relacionamentos.

A produção do conhecimento é fundamental, principalmente quando a informação, os dados e a comunicação junto à organização são levados em consideração. Franco, Rodrigues e Cazela (2012) destacam que a GC se fortalece e se foca na conquista do que chamam de acertos organizacionais. Para os autores, a medida que se utiliza determinada estratégia, estabelece-se motivação aos colaboradores do conhecimento disponível.

Goldman (2010) considerar três gerações da GC: (a) a primeira geração apareceu no final dos anos 1980 e seu foco foi a Tecnologia; (b) a segunda geração surge a partir de 1995 e seu foco são as pessoas; e (c) a terceira geração se estabelece a partir de 2002 e é um misto da primeira e da segunda geração, ou seja, combina a ênfase orientada com a tecnologia.

Observar que o conhecimento, ao ser tratado pelos gestores, conforme a sua importância, pode proporcionar excelentes resultados para uma organização e, assim, auxiliar a tomada de decisão. A gestão percebe em si o valor tanto das pessoas, quanto da tecnologia, da inovação e de outros processos organizacionais. A GC parece ocupar e conquistar as organizações, seja quando surge pela mudança, seja por meio dos líderes, que buscam atingir as metas pela inovação e/ou pela sustentabilidade (MARCANTE et al., 2015).

Segundo Holanda, Dihl e Francisco (2009), os principais autores e suas abordagens sobre GC estão no Quadro 1. 
Quadro 1 - Definições de gestão do conhecimento

\begin{tabular}{|l|l|}
\hline \multicolumn{1}{|c|}{ Autores } & \multicolumn{1}{c|}{ Conceitos } \\
\hline Leonard-Barton (1995) & $\begin{array}{l}\text { Foca-se em atividades que envolvem: } \\
\text { 1) busca de soluções criativas de forma compartilhada; } \\
\text { 2) implementação e integração de novas metodologias e ferramentas } \\
\text { nos processos atuais; } \\
\text { 3) prática de experimentos, a partir de protótipos e projetos piloto } \\
\text { para desenvolvimento de competências; } \\
\text { 4) importação e absorção de metodologias e tecnologias externas. }\end{array}$ \\
\hline $\begin{array}{l}\text { Nonaka e Takeuchi } \\
\text { (1997) }\end{array}$ & $\begin{array}{l}\text { Baseia-se na transformação do conhecimento explícito em conheci- } \\
\text { mento tácito e vice-versa, a partir das práticas de: socialização (tácito } \\
\text { para tácito); externalização (tácito para explícito); combinação (explí- } \\
\text { cito para explícito) e internalização (explícito para tácito). }\end{array}$ \\
\hline Terra (2001) & $\begin{array}{l}\text { Esforça-se para fazer com que o conhecimento de uma organização } \\
\text { esteja disponível àqueles que dele necessitem dentro dela: quando } \\
\text { se faça necessário, onde se faça necessário e na forma como se faça } \\
\text { necessário, com o objetivo de aumentar o desempenho humano e } \\
\text { organizacional. }\end{array}$ \\
\hline $\begin{array}{l}\text { Bukowitz e Williams } \\
\text { (2002) }\end{array}$ & $\begin{array}{l}\text { "É o processo pelo qual a organização gera riqueza, a partir do seu } \\
\text { conhecimento ou capital intelectual" (BUKOW' } \\
\text { p. 75): as autoras desenvolvem um método que realiza o Diagnóstico } \\
\text { da Gestão do Conhecimento (DGC) nas organizações, compreen- } \\
\text { dendo o processo tático e estratégico. }\end{array}$ \\
\hline Choo (2003) & $\begin{array}{l}\text { Baseia-se na organização do conhecimento a partir do uso estraté- } \\
\text { gico da informação. Propõe o ciclo que aborda o uso estratégico da } \\
\text { informação nos processos de construção de sentido, criação de co- } \\
\text { nhecimento e tomada de decisão. Através da interação dessa rede } \\
\text { de processos, os quais estão socialmente distribuídos por muitos ní- } \\
\text { veis e funções da instituição, a organização constrói significados co- } \\
\text { muns sobre sua identidade e sua atividade, gerando o conhecimento } \\
\text { organizacional. }\end{array}$ \\
\hline
\end{tabular}

Fonte: adaptado de Holanda, Dihl e Francisco (2009).

Autores como Barbosa (2009), Wiig (2000) e Jarboe e Alliance (2001) prospectam a visão acerca da GC, através de três percepções distintas. A primeira propõe um olhar a partir do entendimento da lógica cultural e não do comportamento organizacional. Destaca-se a lógica das características administrativas, ainda que a cultura nacional seja bem diferente da cultura anglo-saxônica e/ou oriental, da qual partem os autores (NONAKA; TAKEUCHI, 1997).

A abordagem de Wiig (2000) atenta para a GC na administração pública através das práticas, do gerenciamento, da responsabilidade e da efetividade que 
merece ser aumentada no serviço público. Isso aparece nas ferramentas que auxiliam na atuação dos atores sociais, que se envolvem junto ao processo de desenvolvimento para, assim, realizar as devidas tarefas (JARBOE; ALLIANCE, 2001).

Por outro lado, Firestone e McElroy (2005) procuram identificar a GC não por gerenciar, criar ou integrar, mas por seus resultados organizacionais. Na percepção dos referidos autores, a mesma parte dos processos apenas impactam o conhecimento, inferindo nos demais resultados e, assim, impactar de maneira determinante, proporcionando um aprimoramento de práticas empreendedoras (MARCANTE et al., 2015).

No entanto, a partir do que observam Davenport e Prusak, pode-se definir que o conhecimento age como "um conjunto de fatos distintos e objetivos, relativos a eventos" (1998, p. 2). Seguem destacando que o conhecimento "[...] pode ser comparado a um sistema vivo, que cresce e se modifica a medida que interage com o meio ambiente" (1998, p. 6). Infere-se, diante desses fundamentos, que tudo o que gira em torno dos pensamentos, sejam eles singelos ou brutos, pode ser afirmado através das percepções aplicadas e observadas.

Partindo dos conceitos de conhecimento, pode-se destacar a informação, vista junto aos anseios organizacionais. Constata-se que a informação, nada mais é do que um meio ou uma matéria pelo qual se pode construir um conhecimento ou, ainda, uma mensagem. A informação pode ou não vir a fazer diferença por meio da transmissão e da interpretação de dados, que se disseminam e são incorporadas em produtos e serviços, em tecnologias e sistemas junto à organização (MACHLUP, 2003; DRUCKER, 1999; NONAKA; TAKEUCHI, 2008).

Entretanto, muito mais se deve observar quando se busca empreender a GC junto ao universo organizacional. $\mathrm{O}$ viés público se torna essencial a partir das perspectivas contemporâneas, em que a visão global é importantíssima, principalmente quando se percebe que a tecnocracia, a burocracia e o empreendedorismo podem andar juntos.

\subsection{Geração do conhecimento}

Ao se destacar os principais conceitos relacionados à GC, é plausível atentar para os aportes relativos à geração deste conhecimento. Das razões que justificam a interação em ambientes organizacionais, destaca-se a observação das informações que se transformam em conhecimento, baseada em uma combinação inter-relacionada às várias experiências, aos valores e às regras internas (DAVENPORT; PRUSAK, 1998). Os cinco modos de se gerar conhecimento, identificados pelos autores, aparecem no Quadro 2. 
Quadro 2 - Modos de gerar conhecimento

\begin{tabular}{|l|l|}
\hline \multicolumn{1}{|c|}{ MODOS } & \multicolumn{1}{c|}{ CONCEITOS } \\
\hline Aquisição & $\begin{array}{l}\text { É a maneira mais direta e eficaz de adquirir conhecimento, isto é, } \\
\text { de adquirir uma organização ou de contratar profissionais que o } \\
\text { possuam. Outra maneira de adquirir conhecimento é alugando uma } \\
\text { fonte de conhecimento, como um consultor, por exemplo. Embora } \\
\text { seja uma fonte temporária, parte do conhecimento tende a ficar na } \\
\text { organização. }\end{array}$ \\
\hline Recursos dirigidos & $\begin{array}{l}\text { É a criação de unidades ou de grupos, por exemplo, de departamen- } \\
\text { tos de pesquisa e de desenvolvimento, com a finalidade de produzir } \\
\text { novo conhecimento e novas maneiras de fazer. É uma forma costu- } \\
\text { meira de se gerar conhecimento. }\end{array}$ \\
\hline Fusão & $\begin{array}{l}\text { É a geração de conhecimento por meio de fusão; implica complexi- } \\
\text { dade e conflitos para se criar sinergia, uma vez que reúne pessoas } \\
\text { com diferentes perspectivas para trabalhar em um problema ou pro- } \\
\text { jeto, obrigando-as a chegar a uma resposta conjunta. }\end{array}$ \\
\hline Adaptação & $\begin{array}{l}\text { São as crises no meio ambiente das organizações que atua como } \\
\text { catalisadoras da geração do conhecimento. Às vezes, elas forçam as } \\
\text { organizações a decidirem entre adaptação ou morte. }\end{array}$ \\
\hline $\begin{array}{l}\text { Redes do conhecimento } \\
\text { (comunidades de prática) }\end{array}$ & $\begin{array}{l}\text { São comunidades de possuidores de conhecimento que se unem } \\
\text { por motivos de interesses comuns e interagem por meio de contatos } \\
\text { pessoais, redes sociais, grupos de e-mail, dentre outros. Quando re- } \\
\text { des desse tipo partilham conhecimento suficiente para se comunicar } \\
\text { e cooperar, a continuidade de seu contato costuma gerar novo co- } \\
\text { nhecimento dentro da organização. }\end{array}$ \\
\hline
\end{tabular}

Fonte: adaptado de Davenport e Prusak (1998).

As proposições elencadas pelos autores parecem relacionadas à inovação, às habilidades e ao conhecimentos. Parece representar as mais variadas perspectivas de um indivíduo específico ou, ainda, de um grupo determinado de pessoas. O envolvimento das pessoas e de todas as suas peculiaridades, como seu sentimento ou sua relação, permite observar que o conhecimento organizacional também é gerado pelas redes informais e auto-organizadas. Ou, ainda, é gerado na interpretação de dados e informações, como recursos de informação, experiências, habilidades, cultura, características, personalidade, sentimentos, entre outros (DAVENPORT; PRUSAK, 1998; FRANCO; RODRIGUES; CAZELA, 2012).

No que tange à criação do conhecimento, observa-se literalmente que, de muitas maneiras, a concepção do universo organizacional está disposto e preparado a encontrar. Em sentido prático, isso se justifica a partir da busca por dados, informações e modos que venham gerar e criar conhecimento, desde que o ambiente 
empresarial esteja disposto à aplicação prática, estabelecendo na incorporação a difusão do conhecimento (NONAKA; TAKEUCHI, 2008; FÁTIMA; NASTASI JUNIOR; LIMA JUNIOR, 2015).

Conforme Nonaka e Takeuchi (2008), a GC se divide em duas dimensões, a epistemológica e a ontológica. Segundo os autores, existem outras duas maneiras de conceituar a GC, que são o conhecimento tácito e o conhecimento explicito. Suas definições devem ser tratadas como complementares e jamais podem ser vistas como entidades excludente ou separadas.

Ao partir desse pressuposto de interação entre as formas de conhecimento, os autores definem quatro diferentes modos de conversão, conforme o Quadro 3.

Quadro 3 - Formas do conhecimento

\begin{tabular}{|l|l|}
\hline \multicolumn{1}{|c|}{$\begin{array}{c}\text { Formas do } \\
\text { conhecimento }\end{array}$} & \multicolumn{1}{c|}{ Competição e cooperação } \\
\hline Socialização & $\begin{array}{l}\text { É um processo de compartilhamento de experiências e, a partir daí, da } \\
\text { criação do conhecimento tácito baseado em outros conhecimentos tácitos, } \\
\text { como modelos mentais ou habilidades técnicas compartilhadas. O segredo } \\
\text { é a experiência. Sem alguma forma de experiência compartilhada, é extre- } \\
\text { mamente difícil para uma pessoa projetar-se no processo de raciocínio de } \\
\text { outro indivíduo. }\end{array}$ \\
\hline Externalização & $\begin{array}{l}\text { É um processo de transformação do conhecimento tácito em conceitos ex- } \\
\text { plícitos e ocorre por meio do diálogo ou da reflexão coletiva que o modo } \\
\text { de externalização converte em conhecimento. A externalização é a chave } \\
\text { do conhecimento, pois cria conceitos novos e explícitos a partir do conhe- } \\
\text { cimento tácito. }\end{array}$ \\
\hline Combinação & $\begin{array}{l}\text { É um processo de composição de conceitos, que envolve a combinação de } \\
\text { conjuntos diferentes de conhecimento explícito em um sistema de conhe- } \\
\text { cimento. Os indivíduos trocam e combinam conhecimentos através de do- } \\
\text { cumentos, reuniões, e-mails, dentre outros. O conhecimento existente por } \\
\text { meio do acréscimo, da classificação, da combinação e da categorização do } \\
\text { conhecimento explícito, que pode levar a criação de novos conhecimentos. }\end{array}$ \\
\hline Internalização & $\begin{array}{l}\text { É o processo de incorporação do conhecimento explícito ao conhecimento } \\
\text { tácito, quando os indivíduos, sob a forma de modelos mentais ou know-how } \\
\text { técnico, compartilham as experiências através da socialização, da exter- } \\
\text { nalização e da combinação, tornando-se ativos e valiosos, influenciando a } \\
\text { forma de agir, de pensar e de ver o mundo das pessoas. No entanto, para } \\
\text { viabilizar a criação do conhecimento organizacional, o conhecimento tácito } \\
\text { acumulado precisa ser socializado com os outros membros da organização, } \\
\text { iniciando assim uma nova espiral de criação do conhecimento. }\end{array}$ \\
\hline
\end{tabular}

Fonte: adaptado de Nonaka e Takeuchi (2008). 
De maneira empírica, é apontado pelos autores o fato de que, em linhas gerais, para o conhecimento explícito ser levado em consideração, internalizado e tornar-se um conhecimento tácito, é essencial e necessário a externalização agir através de um meio representativo em que o conhecer se forme através de alguns atributos, tais como, a representação, os documentos, os manuais, as histórias orais, entre outros. Os indivíduos, por sua vez, internalizam suas experiências e, assim, aumentam seu conhecimento tácito.

Conforme Nonaka e Takeuchi, "o conhecimento, diferentemente da informação, refere-se a crenças e compromisso" (1997, p. 63). Aparece, de modo claro, no trabalho dos autores, a classificação do conhecimento humano, retratado no Quadro 4 .

Quadro 4 - Conhecimento humano

\begin{tabular}{|l|l|}
\hline Tipo de conhecimento & \multicolumn{1}{c|}{ Definição } \\
\hline Tácito & $\begin{array}{l}\text { É difícil de ser articulado na linguagem formal um tipo de conhecimen- } \\
\text { to importante. É o conhecimento pessoal incorporado à experiência } \\
\text { individual e envolve fatores intangíveis, como crenças pessoais, pers- } \\
\text { pectivas, sistema de valor, insights, intuições, emoções, habilidades. } \\
\text { Considerado como uma fonte importante de competitividade entre as } \\
\text { organizações, é avaliado por meio da ação. }\end{array}$ \\
\hline \multirow{5}{*}{ Explícito } & $\begin{array}{l}\text { É o que pode ser articulado na linguagem formal, inclusive, em afirma- } \\
\text { ções gramaticais, expressões matemáticas, especificações, manuais } \\
\text { etc., facilmente transmitido, sistematizado e comunicado. Pode ser } \\
\text { transmitido formal e facilmente entre os indivíduos. Esse foi o modo } \\
\text { dominante de conhecimento na tradição filosófica ocidental. }\end{array}$ \\
\hline
\end{tabular}

Fonte: adaptado de Nonaka e Takeuchi (2008).

Do quadro anterior, observa-se a inter-relação existente entre o conhecimento tácito e o conhecimento explícito. A cooperação ou o aporte de qualquer insumo que venha a dimensionar os processos relacionados à organização parecem, em muito, qualificar a apresentação de ambos os conhecimentos e, assim, propor que os gerentes e os executores possam fortalecer seus vínculos e inferir juntos o ambiente interno e o ambiente externo.

A GC, ao longo de sua trajetória, busca o estímulo da criação de novas ferramentas, especialmente em termos de inovação para o universo organizacional. Captar informações e dados, difundir a comunicação e utilizar-se das mais variadas formas de conhecimento tendem a proporcionar benefícios à empresa e a auxiliá-la. O compartilhamento, a criação e a aquisição, a inovação, a continuidade do negócio e o aumento da eficiência e da eficácia podem se tornar rotinas administrativas 
importantes para a organização (OLIVEIRA; CALDEIRA; ROMÃO, 2014; AMAYAH, 2013; RAGAB; ARISHA, 2013; e FAORO; OLIVEIRA, 2014).

Marcante et al. (2015) reconhecem que a GC está conquistando o seu espaço e o seu maior destaque são as mudanças proporcionadas às lideranças no seu desempenho, buscando alcançar metas importantes em inovação e sustentabilidade. Isso converge para o aumento da confiabilidade e o auxílio na tomada de decisões organizacionais, pois compartilhar o conhecimento é primordial para o fomento de mecanismos de aprendizagem (POKHAREL; CHOI, 2015).

\section{2 Diagnósticos, avaliação, modelos e classificação das ferramentas da gestão do conhecimento}

A concepção administrativa permite compreender a existência de um novo paradigma, que deve ser quebrado e desenvolvido. Drucker explica que somente a organização "pode oferecer a continuidade básica de que os trabalhadores do conhecimento precisam para serem eficazes" e completa: "[...] apenas ela pode transformar o conhecimento especializado do trabalhador no conhecimento de desempenho" (1999, p. 40).

Probst, Raub e Romhardt (2002), Orr e Persson (2003), Carvalho (2003), Hanleye Malafsky (2004), Kaplan e Norton (2004), Fonseca (2006), entre outros, apresentam algumas considerações acerca dos diagnósticos, das avaliações e das classificação da GC. Para os autores, essas ferramentas são fundamentais, para que os gestores tenham acesso aos elementos e às informações necessárias que irão auxiliá-los na tomada de decisão.

Em complemento a isso, Sandhu, Jain e Ahmad (2009), destacam que os desafios para a implementação da GC encontram-se em três categorias, assim classificadas:

1) Individual, são as barreiras de personalidade (habilidades de comunicação, estabelecimento de redes sociais, diferenças culturais, falta de motivação, falta de confiança, medo de não ser reconhecido);

2) Organizacional, são as categorias de origem própria da organização (gerência, práticas ineficazes, infraestrutura inadequada, competição interna, falta de recompensas, falta de apoio da alta administração, falta de capacitação);

3) Tecnológica, é a ausência de interoperabilidade entre os sistemas (falta de suporte técnico, relutância das pessoas no uso das tecnologias, falta de capacitação para familiarização dos sistemas de tecnologia da informação). 
Quanto aos modelos da GC, baseados em Castro (2005), apresenta-se o Quadro 5.

Quadro 5 - Modelos da GC

\begin{tabular}{|l|l|l|}
\hline \multicolumn{1}{|c|}{ Modelo } & \multicolumn{1}{|c|}{ Autores } & \multicolumn{1}{c|}{ Foco } \\
\hline $\begin{array}{l}\text { Criação do Conhecimento } \\
\text { (Espiral) }\end{array}$ & $\begin{array}{l}\text { Nonaka e Takeuchi } \\
(1997)\end{array}$ & $\begin{array}{l}\text { Processo de criação do conhecimento orga- } \\
\text { nizacional voltado para o desenvolvimento } \\
\text { de produtos/serviços, processos e gestão }\end{array}$ \\
\hline $\begin{array}{l}\text { Sete Dimensões da gestão } \\
\text { do conhecimento }\end{array}$ & Terra (2001) & $\begin{array}{l}\text { Avaliação da GC nas organizações, consi- } \\
\text { derando as dimensões da prática gerencial }\end{array}$ \\
\hline $\begin{array}{l}\text { Elementos Construtivos da } \\
\text { Gestão do conhecimento }\end{array}$ & $\begin{array}{l}\text { Probst, Raub e } \\
\text { Romhardt (2002) }\end{array}$ & $\begin{array}{l}\text { Análise e aplicação da GC com base nos } \\
\text { elementos construtivos }\end{array}$ \\
\hline $\begin{array}{l}\text { Diagnóstico de Gestão do } \\
\text { Conhecimento }\end{array}$ & $\begin{array}{l}\text { Bukowitz e Williams } \\
(2002)\end{array}$ & $\begin{array}{l}\text { Estruturação nos processos de GC com } \\
\text { base no diagnóstico. }\end{array}$ \\
\hline
\end{tabular}

Fonte: adaptado de Castro (2005).

Diante do que se observa como primordial em termos gerenciais, não basta destacar apenas os avanços que determinadas quebras de regras possam vir a interferir junto à administração. A reflexão acerca dos significados de gestão, igualmente complementados pelo que a comunidade e seus agentes pretendem, aparece também a partir do rompimento do paradigma usual. Processos como aqueles orientados no sentido da observância da eficácia e da eficiência, principalmente, tendem a ser afirmados pelas teorias weberianas, em que a burocratização aparece como elemento fundamental.

Para Jennex, Olfma e Addo (2002) se deve procurar considerar o conhecimento como uma mistura, em que se leva em consideração o que se entende por experiência estruturada; por valores ou por informação contextual, e/ou, ainda, pelo que se determina ser o discernimento especializado. Conforme os autores, todo esse processo ou, ao menos, boa parte dele pode vir a fornecer uma estrutura organizacional mais sólida, que, de várias maneiras, facilitará as avaliações e as incorporações das novas experiências e das novas informações que, por ventura, vierem a acontecer.

Pode-se observar que os administradores e os pesquisadores, de um modo em geral, estão atentos à velocidade que os ativos intelectuais estão sendo desenvolvidos junto à organização (TEECE; PISANO; SHUEN, 1998; WEE; CHUA, 2013; PANAHI; WATSON; PARTRIDGE, 2013). Quando se identifica a existência de 
determinados desenhos de mecanismos e ações de GC, maximiza-se a produtividade empresarial (POKHAREL; CHOI, 2015).

É importante destacar quando se pode compreender o conhecimento de uma maneira mais real, ou seja, quando o conhecimento é recebido. A sua utilização e utilidade dependem da capacidade de as pessoas conseguirem absorvê-lo. Isso aparece, nas organizações, a partir dos processos, das práticas, das normas, dentre outras percepções identificadas no modelo da Figura 1.

Figura 1 - Espiral do conhecimento

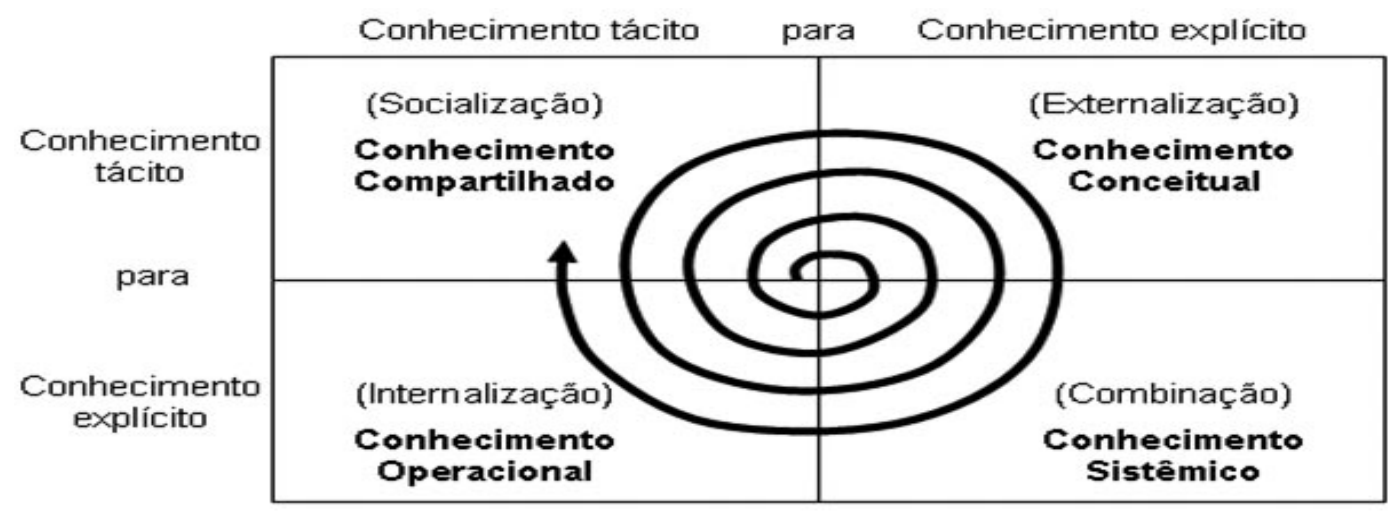

Fonte: Nonaka e Takeuchi (1997).

Conforme Nonaka e Takeuchi, quando uma empresa se propõe a gerar o conhecimento, "deve completar uma 'espiral do conhecimento', espiral esta que vai de tácito para tácito, de explícito a explícito, de tácito a explícito, e finalmente, de explícito a tácito" (1997, p. 79). A espiral complementa-se a partir da ideia de cumplicidade que pode vir a ser vivenciada pelos gerentes e pelos colaboradores, quando os mesmos unem-se na organização.

Para Carvalho (2012), existe outro modo de conversão, quando se visualiza o conhecimento, denominados de níveis ontológicos. Segundo o autor, as entidades que criam conhecimento são: o indivíduo, o grupo, a organização, a interorganização.

Em complemento a isso, Figueiredo (2005) define que existe ainda uma terceira divisão que se completa a essa duas: o conhecimento potencial. Para o autor, essa outra etapa ocorre a partir da obtenção ou da extração de novos conhecimentos, resultantes da potencialidade de se ter grandes volumes de dados. Pode-se determinar que a GC é, sobretudo, compartilhamento, criação e inovação (TERRA, 2012).

Na sequência, visualiza-se, na Figura 2, as sete dimensões da GC. 
Figura 2 - As sete dimensões da gestão do conhecimento

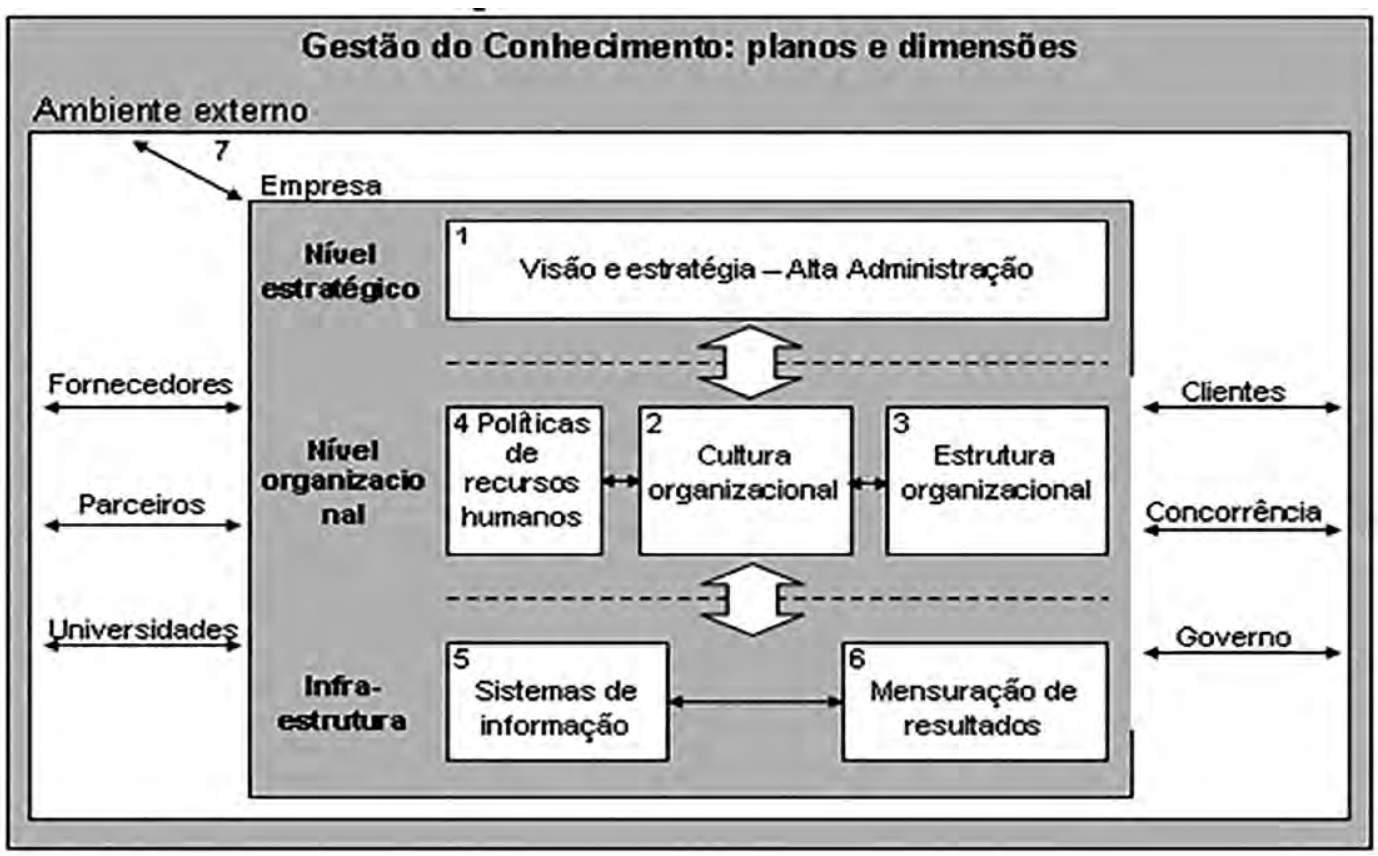

Fonte: Terra (2001).

$\mathrm{Na}$ figura anterior, apresenta-se o capital humano como aspecto primordial. Dessa perspectiva, as organizações precisam buscar compreender seus ambientes, ter troca de conhecimento, atender seus colaboradores, fomentar a inovação, trocar informações, compartilhar experiências e habilidades. Perceber que as ideias, de várias formas, causam um maior impacto, quando são disseminadas e não quando ficam somente em poder de algumas pessoas (GARVIN, 2000).

A partir da utilização de ferramentas que possam auxiliar a GC, existem alguns aspectos relevantes que surgem como fatores corriqueiros ou diários, ocorridos nas empresas. Identificá-los, nas ações realizadas por equipes multidisciplinares, de certa maneira, pode auxiliar no ensino, na criação do conhecimento, na descentralização e, especialmente, na tomada de decisão (FÁTIMA; NASTASI JUNIOR; LIMA JUNIOR, 2015). Para os autores, isso, em si, completa-se quando os gerentes promovem maior liberdade, aumentando a autonomia dos colaboradores por intermédio de programas em que os mesmos venham a aprender com seus próprios erros.

Conforme Nonaka e Takeuchi (1997) e Probst, Raub e Romhardt (2002), pode-se determinar os processos de GC como indispensáveis para as organizações, tanto 
as identificadas com viés privado, como as de viés público. Partindo dos pressupostos de compartilhamento e de inter-relação, os autores definem os seguintes elementos: identificação, aquisição, desenvolvimento, compartilhamento, utilização, retenção do conhecimento.

Esses elementos estão representados na Figura 3.

Figura 3 - Elementos construtivos da gestão do conhecimento

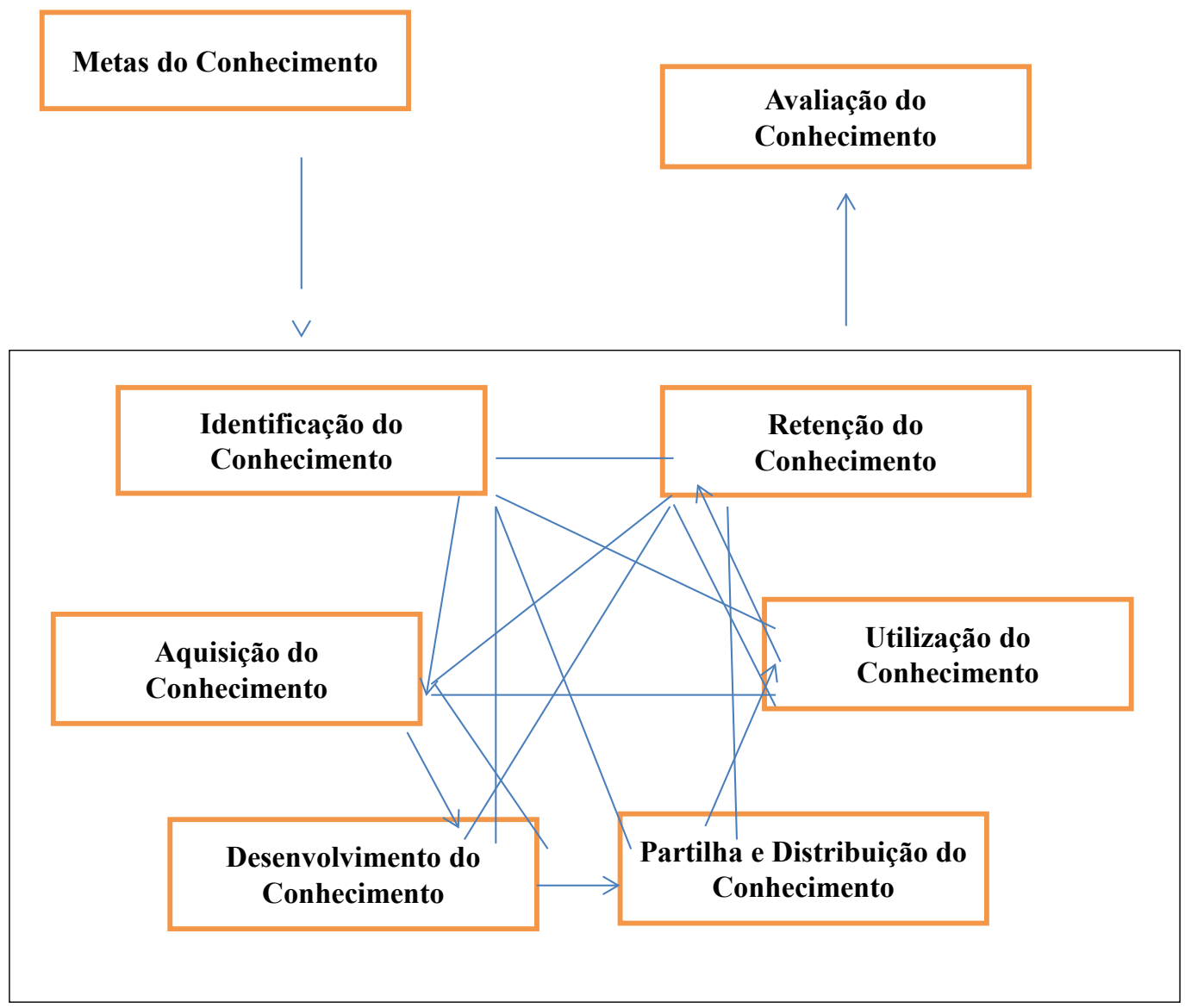

Fonte: Probst, Raub e Romhardt (2002).

Os autores propõem-se apresentar um modelo de análise que identifica os processos considerados essenciais para a implementação da GC. Os mesmos buscam alertar acerca dos riscos de se tentar otimizar as atividades de conhecimento em 
área ditas individuais, sem que, para isso, venham a considerar a organização como um todo, com sua amplitude e seus efeitos.

A percepção dos autores requer o estabelecimento, a partir desses elementos, da relevância da GC a todas as organizações. A identificação, a aquisição, o desenvolvimento, a partilha/distribuição, a retenção e a utilização do conhecimento são processos, mecanismos e modelos gerenciais importantíssimos.

Batista, Rosenberg, e Ohayon (2002), observam que, ao se ter maior eficiência junto ao meio empresarial, converge-se, de muitas maneiras, para a melhoria das práticas de GC. Para os autores, nessa lógica, existe um grau maior de relacionamentos institucionais, devido ao aumento de atributos, como a transparência, aliado ao crescimento dos investimentos feitos em tecnologias de informação e de comunicação.

Baseados nesses preceitos empresariais e de gestão, alude-se a existência de processos de GC que possam vir a possibilitar uma melhor estruturação (NONAKA; TAKEUCHI, 1997), conforme a Figura 4.

Figura 4 - Estruturação dos processos de GC

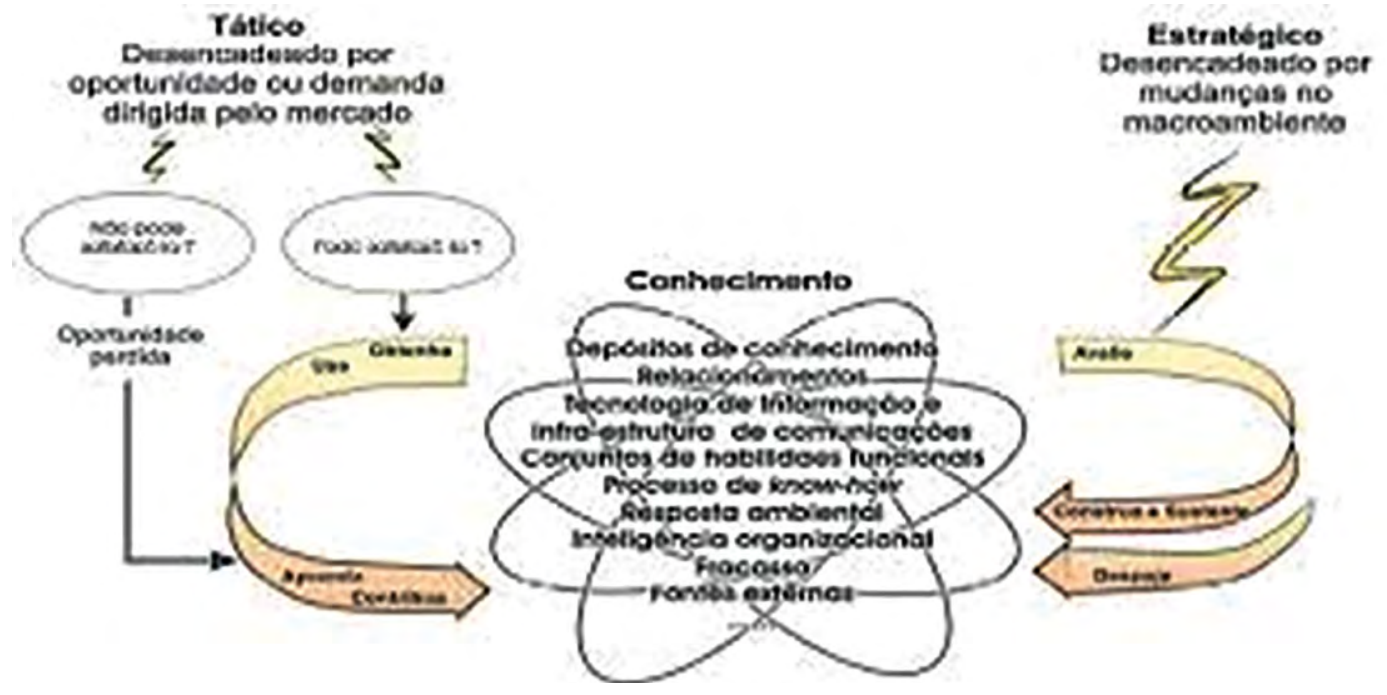

Fonte: Bukowitz e Williams (2002).

Diante dos aspectos táticos retratados por Bokowitz e Willians (2002), percebe-se que o conhecimento gera valor. As autoras ainda destacam que a obtenção, a utilização, o aprendizado e as contribuições podem vir a ser fundamentais na GC, uma vez que as informações, as fontes, as pessoas, os relacionamentos, o trabalho, o conhecimento, entre outros, aparecem como matérias-primas para a crescimento 
e o desenvolvimento de todos os agentes envolvidos. A tendência é confirmar a visão das autoras, quando elas identificam que o processo estratégico é também uma continuidade da avaliação acerca do capital intelectual.

Por outro lado, a participação de grupos, de lideranças organizacionais e dos vários processos de planejamento, que venham a mapear e a avaliar as necessidades da organização, aparecem nas ferramentas da GC, conforme o Quadro 6.

Quadro 6 - Apresentação das ferramentas de gestão do conhecimento

\begin{tabular}{|c|c|c|}
\hline Autores & Carvalho (2003) & $\begin{array}{l}\text { Braga (2002); Borges Júnior et al. (2004); } \\
\text { Lukács (2005); Reis e Barros (2005) }\end{array}$ \\
\hline Ferramentas & $\begin{array}{l}\text { - intranets; } \\
\text { - gerenciamento eletrônico de docu- } \\
\text { mentos (GED); } \\
\text { - groupware; } \\
\text { - workflow; } \\
\text { - bases inteligentes de conhecimento; } \\
\text { - business intelligence; } \\
\text { - mapas de conhecimento; } \\
\text { - ferramentas de apoio à inovação; } \\
\text { - sistemas de inteligência competitiva; } \\
\text { - portais corporativos. }\end{array}$ & $\begin{array}{l}\text { - balanced scorecard (BSC); } \\
\text { - total productive maintenance (TPM); } \\
\text { - treinamento e desenvolvimento; } \\
\text { - kaizen; } \\
\text { - Sistema de informação; } \\
\text { - produção enxuta; } \\
\text { - } 5 \text { S's (housekeeping); } \\
\text { - padronização; } \\
\text { - equipes semiautônomas de alta perfor- } \\
\text { mance. }\end{array}$ \\
\hline
\end{tabular}

Fonte: elaborado pelos autores (2016).

Observa-se, no quadro anterior, o grande número de ferramentas que podem ser implementado na GC. A escolha de qualquer uma contempla o projeto de cada organização ou, ainda, a maneira pela qual a empresa melhor se identifica. $O$ viés organizacional percebido junto desse ambiente pode, de muitas formas, vir acompanhado da proposição ou da premissa definida pelos gestores ou pela alta gerência, desde que se permita inferir o que a mesma se propõe como organização.

\section{A administração pública gerencial}

Após anos de um modelo governamental burocrático, destacado e solidificado por em uma dimensão firme e orientada, a administração pública brasileira buscou uma saída para as muitas crises nacionais através da reforma gerencial de 1995, 
pautada pelos princípios da nova gestão pública (new public management). A quebra de um paradigma, que se deu com a derrubada de sistemas lentos, morosos, dos mais variados entraves da parte ativa da gestão, parece ter sido essencial para esse modelo, que, entre outras questões, busca mudar a sociedade através de transformações institucionais, situação comum no contexto político da América Latina (BRESSER-PEREIRA, 1996, p. 6).

Conforme Di Pietro, as novas estratégicas e formulação de políticas contemporâneas trouxeram maior autonomia às atividades reconhecidas pelo estado e, assim, completa a autora, foi possível, através da descentralização administrativa, que:

[...] ocorre quando as atribuições que os entes descentralizados exercem só têm o valor jurídico que lhes empresta o ente central; suas atribuições não decorrem, com força própria, da Constituição, mas do poder central. É o tipo de descentralização própria dos Estados unitários, em que há um centro único de poder, do qual se destacam, com relação de subordinação, os poderes das pessoas jurídicas locais (2010, p. 411).

Conforme Bresser-Pereira (1999b), a reforma gerencial se utilizou de alguns mecanismos para a sua completa execução. Dentre eles, destacam-se:

- Contratos de gestão - que definem os indicadores de desempenho a serem alcançados pelas instituições;

- Estratégia de gerenciamento da ideia da "Gestão pela qualidade total" - que utiliza vários critérios empresariais adequados ao gerenciamento público por adotar vários quesitos de excelência, além das simples taxas de juros;

- Acolhimento de uma demanda social real - que influencia o cotidiano dos cidadãos com o auxílio da mídia.

O momento vivenciado pelo poder Público, em que uma série de vícios estavam embrenhados nas mais variadas instituições, parece ter determinado que uma mudança de paradigma fosse premente e necessária. A busca por melhores resultados, em termos de desempenho institucional, que abrangesse o Estado como um todo, proporcionando maior qualidade nos serviços públicos e também junto aos servidores, apresentou-se como um salto em termos de gerenciamento e gestão.

A quebra do modelo burocrático, em que se demonstrava certo colapso administrativo, tende a embasar a busca pela idealização de um novo jeito de administrar. A criação de novas instituições e a criação de um plano diretor, aliado às novas práticas gerencias, possibilitaram maior flexibilização nos regulamentos, veja-se a proliferação da ideologia das privatizações frente à escassez dos recursos públicos e também aos processos burocráticos que, de uma forma ou outra, conferiram maior autonomia às agências governamentais (BRESSER-PEREIRA, 1999a). 
Já, para Secchi (2009), os exemplos de valores da administração pública gerencial são: a produtividade, a descentralização, a eficiência na prestação de serviços, a accountability, entre outros. Entretanto, o Centro Latino-Americano de Administração para o Desenvolvimento (CLAD, 1998) apresenta como características principais do modelo gerencial: a profissionalização da alta burocracia, a transparência da administração pública, a descentralização da execução dos serviços públicos, a desconcentração organizacional nas atividades exclusivas do Estado e a orientação para o controle de resultados.

Segundo Modesto (1997), pode-se acrescentar a essas características, o estímulo à privatização, a capacitação de pessoal dirigente, a criação de carreiras específicas para altos gestores, a elaboração do conceito de planejamento estratégico, dentre outras. Isso, pois, deixa evidente que o referido modelo gerencial apresenta uma inspiração pertinente às transformações do setor privado, em que aspectos como a busca pela flexibilização de gestão e a procura pela redução dos níveis hierárquicos, aliados ao aumento da autonomia gerencial na tomada de decisão, são destaques (CLAD, 1998).

Por outro lado, de Paula infere que "esse é ainda um projeto em construção" (2005, p. 47). O autor segue seu raciocínio, observando que a complementação do modelo gerencial não se concretizou no Brasil, por isso aparece como projeto inacabado. E conclui que, ao se visualizar a nova administração pública brasileira, ela prescinde ser reinventada. Para isso, utilizar-se de reflexões a respeito dos processos de reforma e busca construir um novo modelo, cujo objetivo seja, principalmente, dirimir as possíveis vulnerabilidades e reencontrar os melhores preceitos administrativos.

\subsection{Princípios da administração pública}

A administração pública brasileira, assim como qualquer gestão organizacional, prescinde respeitar alguns preceitos e princípios. Isso se enaltece a partir da significação de que as contribuições institucionais possam trazer processos concretos de maioridade nacional. Pressupõe-se a isso a grande importância que se pode atribuir aos cuidados com os meios produtivos e organizacionais inerentes e presentes dentro do país.

Diante dos ideais republicanos e em respeito ao Estado Democrático de Direito, não parece ser crível que uma nação encontre na arbitrariedade a justificativa para sua autoridade administrativa. Isso tende a ser matéria já amplamente discutida junto aos meios jurídicos e jurisdicionais, em que a Lei se reforma, mas, 
em momento algum, se alimenta de abusos e de outras questões que não sejam de interesse público.

Para Di Pietro, pode-se determinar que:

Sobremodo no Estado de Direito, repugnaria ao senso normal dos homens que a existência de discrição administrativa fosse um salvo conduto para a administração agir de modo incoerente, ilógico, desarrazoado e o fizesse precisamente a título de cumprir uma finalidade legal, quando - conforme se viu - a discrição representa, justamente, margem de liberdade para eleger a conduta mais clarividente, mais percuciente ante as circunstâncias concretas, de modo a satisfazer com a máxima precisão o escopo da norma que outorgou esta liberdade. Também não se poderiam admitir medidas desproporcionadas em relação às circunstâncias que suscitaram o ato - e, portanto, assintônicas com o fim legal - não apenas porque conduta desproporcional é, assim mesma, comportamento desarrazoado, mas também porque representaria um extravasamento de competência (2010, p. 194).

Assim, pode-se destacar que os princípios que orientam e balizam a administração pública brasileira (BRASIL, 1988) são: o princípio da Legalidade, o princípio da Moralidade, o princípio da Impessoalidade, o princípio da Razoabilidade e da Proporcionalidade, o princípio da Publicidade, o princípio da Eficiência, o princípio do Interesse Público, entre outros.

$\mathrm{O}$ fato de se destacarem esses princípios como os principais, baseia-se no fato de que os mesmos apresentam-se como os mais afeitos a suscitar a indicação da eficiência ou da ineficiência dos modelos gerenciais existentes. A democracia parece ser um eixo indutor da governabilidade e, como tal, possibilita visualizar sua presença na vida dos cidadãos, aparecendo como destaque o respeito pelas regras básicas da convivência e da participação de todos na sociedade.

Baseado no que traz a Constituição Federal de 1988, em especial, o seu artigo 37, a relevância dos Princípios da Administração Pública podem ser visualizados no Quadro 7. 
Quadro 7 - Princípios da administração pública brasileira

\begin{tabular}{|c|c|}
\hline Princípios & Conceitos \\
\hline Legalidade & $\begin{array}{l}\text { Na Administração Pública, não há liberdade nem vontade pes- } \\
\text { soal. Enquanto na administração particular é lícito fazer tudo que } \\
\text { a lei não proíbe, na Administração Pública só é permitido fazer } \\
\text { o que a lei autoriza. A lei, para o particular, significa "poder fazer } \\
\text { assim"; para o administrador público, significa "deve fazer assim". }\end{array}$ \\
\hline Moralidade & $\begin{array}{l}\text { É certo que a moralidade do ato administrativo, juntamente a sua } \\
\text { legalidade e finalidade, além de sua adequação aos demais prin- } \\
\text { cípios, constitui pressupostos de validade, sem os quais toda ati- } \\
\text { vidade pública será ilegítima. }\end{array}$ \\
\hline Impessoalidade & $\begin{array}{l}\text { O princípio da impessoalidade, referido na Constituição de } 1988 \\
\text { (art. } 37 \text {, caput), nada mais é do que o clássico princípio da finali- } \\
\text { dade, que impõe ao administrador público que só pratique o ato } \\
\text { para o seu fim legal. E o fim legal é unicamente aquele em que a } \\
\text { norma de direito indica, expressa ou virtualmente, como objetivo } \\
\text { do ato a forma impessoal. }\end{array}$ \\
\hline $\begin{array}{l}\text { Razoabilidade e } \\
\text { proporcionalidade }\end{array}$ & $\begin{array}{l}\text { O princípio da razoabilidade ou proporcionalidade, implícito na } \\
\text { Constituição Federal, também chamado de princípio da proibição } \\
\text { de excesso, tem como intuito evitar restrições desnecessárias ou } \\
\text { abusivas por parte da Administração Pública, com lesão aos di- } \\
\text { reitos fundamentais, aferindo a compatibilidade entre os meios e } \\
\text { fins. }\end{array}$ \\
\hline Publicidade & $\begin{array}{l}\text { A publicidade, como princípio da administração pública, abrange } \\
\text { toda atuação estatal, não só sob o aspecto de divulgação oficial } \\
\text { de seus atos, como também de propiciação de conhecimento da } \\
\text { conduta interna de seus agentes. }\end{array}$ \\
\hline Eficiência & $\begin{array}{l}\text { O Princípio da eficiência exige que a atividade administrativa seja } \\
\text { exercida com presteza, perfeição e rendimento funcional. É o } \\
\text { mais moderno princípio da função administrativa, que já não se } \\
\text { contenta em desempenhar apenas com uma legalidade, exigindo } \\
\text { resultados positivos para o serviço público e satisfatório atendi- } \\
\text { mento às necessidades da comunidade e de seus membros. }\end{array}$ \\
\hline Interesse público & $\begin{array}{l}\text { Com o nome de interesse público, a Lei } 9.784 / 99 \text { coloca-o como } \\
\text { um dos princípios de observância obrigatória pela Administração } \\
\text { Pública, correspondendo ao "atendimento a fins de interesse ge- } \\
\text { ral vedada a renúncia total ou parcial de poderes ou competência, } \\
\text { salvo autorização em lei". }\end{array}$ \\
\hline
\end{tabular}

Fonte: adaptado de Meirelles (2000).

Contudo, parece ser premente salientar que a idealização de leis, de regramentos e de regulamentações junto aos preceitos de Estado parece inferir uma ideia de que existe sempre uma segurança jurídica. Ou seja, o que os Princípios Constitucionais tendem a buscar, reside no fato de que, tanto nos meios públicos, como nos meios privados, é imprescindível que as instituições, bem como os indivíduos, tenham a garantia, por parte do Estado, de que seus direitos e deveres sejam resguardados. 


\section{$3.2 \mathrm{O}$ governo}

Buscando entender como se conceitua e se contextualiza uma esfera institucional, é essencial apresentar a ideia de governo e suas premissas. Ao se retratar a maioridade político-administrativa de um Estado, o entendimento e a compreensão de como o mesmo está localizado e aparelhado aparece como primordial, ainda mais quando se pretende identificar a história de uma sociedade.

Segundo a Osborne e Gaebler (1994), o governo se apresenta como empresarial/empreendedor e se fundamenta segundo o Quadro 8.

Quadro 8 - Princípios do Governo Empresarial/Empregador

\begin{tabular}{|c|c|}
\hline \multicolumn{2}{|r|}{ Tipos de Governo } \\
\hline Governo Catalisador & $\begin{array}{l}\text { Deve assumir o papel daquele que aplica as políticas públicas e har- } \\
\text { moniza a ação de diferentes agentes sociais na solução de problemas } \\
\text { coletivos. }\end{array}$ \\
\hline Governo Competitivo & $\begin{array}{l}\text { Deve criar mecanismos de competição dentro das organizações públicas } \\
\text { e, entre organizações públicas e privadas, buscar fomentar a melhora da } \\
\text { qualidade dos serviços prestados. Essa prescrição é contrária os mono- } \\
\text { pólios governamentais na prestação de certos serviços públicos. }\end{array}$ \\
\hline $\begin{array}{l}\text { Governo } \\
\text { da Comunidade }\end{array}$ & $\begin{array}{l}\text { Deve se abrir à participação dos cidadãos no momento de tomada de } \\
\text { decisão. }\end{array}$ \\
\hline $\begin{array}{l}\text { Governo Orientado } \\
\text { por Missões }\end{array}$ & $\begin{array}{l}\text { Deve deixar de lado a obsessão pelo seguimento de normativas formais } \\
\text { e migrar a atenção na direção da sua verdadeira missão. }\end{array}$ \\
\hline $\begin{array}{l}\text { Governo Voltado para } \\
\text { Clientes }\end{array}$ & $\begin{array}{l}\text { Deve substituir a autorreferencialidade pela lógica de atenção às neces- } \\
\text { sidades dos clientes/cidadãos. }\end{array}$ \\
\hline $\begin{array}{l}\text { Governo } \\
\text { de Resultados }\end{array}$ & $\begin{array}{l}\text { Deve substituir o foco no controle de inputs para o controle de outputs } \\
\text { e os impactos de suas ações, para isso adota-se a administração por } \\
\text { objetivos. }\end{array}$ \\
\hline Governo Empreendedor & $\begin{array}{l}\text { Deve se esforçar para aumentar seus ganhos por meio de aplicações } \\
\text { financeiras e de ampliação da prestação de serviços. }\end{array}$ \\
\hline Governo Preventivo & $\begin{array}{l}\text { Deve abandonar comportamentos reativos na solução de problemas } \\
\text { pela ação proativa, elaborando planejamento estratégico, para antever } \\
\text { problemas potenciais. }\end{array}$ \\
\hline Governo Descentralizado & $\begin{array}{l}\text { Deve envolver os funcionários nos processos deliberativos, aproveitando } \\
\text { o seu conhecimento e a sua capacidade inovadora. Além de melhorar a } \\
\text { capacidade de inovação e resolução de problemas, a descentralização } \\
\text { também é apresentada como forma de aumentar a motivação e a au- } \\
\text { toestima dos funcionários públicos. }\end{array}$ \\
\hline $\begin{array}{l}\text { Governo Orientado } \\
\text { para o Mercado }\end{array}$ & $\begin{array}{l}\text { Deve promover a lógica competitiva de mercado e adentrá-la, investindo } \\
\text { dinheiro em aplicações de risco, agindo como intermediário na prestação } \\
\text { de certos serviços, criando agências regulatórias e institutos para pres- } \\
\text { tação de informação relevante e, assim, abatendo custos transacionais. }\end{array}$ \\
\hline
\end{tabular}

Fonte: adaptado de Osborne e Gaebler (1994). 
Assim, há de se estabelecer sempre uma ideia de funcionalidade, aliada ao bem comum e a satisfação dos agentes e do cliente final. Parece não ser nada estimulante que, ainda no momento atual, qualquer que seja a administração, se esconda, sob a égide política, uma total dissonância de gestão, ou mesmo de política, que, em si, tende a ferir a realidade das organizações e das instituições e refletir em toda a sociedade.

O papel do governo em si aparece nas ações que o mesmo utiliza corriqueiramente, ou seja, começa na sua estrutura e passa pela necessidade de atender a sociedade como um todo, sem deixar de estabelecer na figura do indivíduo um agente importante. Isso se encontra na sistematização de um conhecimento, que deve ser público, para, então, transformá-lo em uma forma de valor a toda a sociedade, destacando-se como um grande desafio para o governo (FRESNEDA; GONÇALVES, 2007).

Assim, Osborne e Gaebler (1994) propõem que o governo pode ser visto em dez princípios básicos pós-modelo burocrático. Para os autores, todo esse processo aparece inserido no contexto do que representa o governo, suas particularidades e singularidades, apresentados no Quadro 9.

Quadro 9 - Princípios básicos do modelo pós-burocrático

1. Competição entre os prestadores de serviço público.

2. Poder aos cidadãos, transferindo o controle das atividades à comunidade.

3. Medição da atuação das agências governamentais através dos resultados.

4. Orientação por objetivos, não por regras e regulamentos.

5. Redefinição dos usuários como clientes.

6. Atuação na prevenção dos problemas mais do que no tratamento.

7. Prioridade de investimento na produção de recursos, não em seu gasto.

8. Descentralização da autoridade.

9. Preferência pelos mecanismos de mercado às soluções burocráticas.

10. Catalisação da ação dos setores público, privado e voluntário.

Fonte: Osborne e Gaebler (1994).

\subsection{Gestão do conhecimento no serviço público}

A partir da proposta de definir uma GC sustentável e dinâmica junto a administração pública, a muitos atributos se pode aludir. Seja através dos grandes avanços tecnológicos, seja diante da velocidade de informações, o importante para o momento advém do fato de que as organizações públicas, na grande maioria de suas funcionalidades, prescindem ser ágeis, eficientes e eficazes. 
Os autores Abdullah e Date (2009) citam algumas razões, em que identificam a similaridade entre os setores público e privado, em especial, aquelas que tratam da GC. São elas: atrair e manter o capital humano; promover o capital social criando e usando o capital estrutural; compartilhar processos e melhores práticas, em combinação com práticas inovadoras; estimular a colaboração.

A observação do modo como a organização pública, já há algum tempo, parece se ater a um novo cenário, aparece nos investimentos em recursos que as gestões estejam definindo. A busca por esforços e a promoção de ferramentas internas e externas, que, em si, requerem adquirir o conhecimento e o equilíbrio entre a criação e a transferência desses dados e informações, aparecem como essenciais. A administração pública se afirma por meio das suas ações e sucessos, sempre visualizando a competitividade de uma organização (DIXON, 2000; SYED-IKHSAN; ROWLAND, 2004).

Por outro lado, Cong e Pandya (2003) e Salavati, Shafei e Shaghayegh (2010) discordam dessa percepção e argumentam que se faz necessário um modelo genérico de GC exclusivamente para o setor público. Ajustificativa para essas considerações, segundo seus autores, parte da simples constatação de que existem diferenças entre o setor público e o setor privado.

Conforme Wiig (2000), pode-se destacar que a GC contribui com novas opções, melhorando a capacidade de realização com práticas que podem beneficiar muito a administração pública. Gerenciar o conhecimento se tornou uma nova responsabilidade da gestão, para que ela possa aumentar a efetividade dos serviços públicos e, assim, melhorar a sociedade a qual serve.

A busca para um modelo exclusivo da GC junto ao setor público encontra ressonância no fato de que esse viés tem suas particularidades e especificidades, diferentemente do modelo privado. A existência de um sistema que apoie a administração pública, proporcionando ampla sustentação, ainda que não busque a competição, mas a prestação de serviços, aparece como fundamental. O destaque surge quando esse compartilhamento e esse uso do conhecimento chega até a sociedade, trazendo soluções e atendendo suas necessidades. Constata-se isso na percepção do aumento da visibilidade das pessoas, das instituições e de seus conceitos, em que seus agentes venham a trabalhar de maneira mais inteligente (CONG; PANDYA, 2003; WIIG, 2002; MONAVVARIAN; KASAEI, 2007).

Segundo Baracchini (2002), há de se observar que, em se tratando da esfera local onde o governo esteja empenhado na mudança de paradigmas e de políticas há muito empregadas, algo novo deve ser perseguido. $\mathrm{O}$ autor ainda complementa que tal mudança de padrão, conforme o olhar brasileiro, se atém a um processo de 
construção das novas formas de gestão, em que a prestação de serviços públicos à população aparece como primordial.

Segundo Terra (2001), Alvarenga Neto e Vieira (2011), alguns modelos de GC do setor público podem acarretar a "Mensuração de Resultados". O encontro desses resultados significa a aplicação de processos, de produtos e de serviços. Observa-se, então, que se pode permitir muitas formas de avaliações e de comparações através de metas, de padrões, de resultados anteriores da organização e de resultados de outras organizações (NATIONAL INSTITUTE OF STANDARDS AND TECHNOLOGY, 2006).

Em complemento a isso, a Asian Productivity Organization (APO, 2009) identifica alguns resultados organizacionais, tais como:

- Aumento da produtividade mediante redução de custos, aumento da efetividade, uso mais eficiente dos recursos (incluindo conhecimento), melhoria do processo de decisão e aumento na rapidez da inovação;

- Aumento da lucratividade como resultado da produtividade, da qualidade e das melhorias na satisfação do cliente;

- Aumento da qualidade dos produtos e serviços como resultado da aplicação do conhecimento, para melhorar os processos de trabalho e de relacionamento com os clientes;

- Manutenção do crescimento como resultado de uma maior produtividade, aumento da lucratividade e melhora da qualidade de produtos e serviços.

Indo mais além, Rubenstein-Montano et al. (2001), Weber et al. (2002) e Heisig (2009) apresentam as seguintes definições para os modelos necessários da GC na administração pública, conforme o Quadro 10.

Quadro 10 - Tipos de modelos da GC no setor público

\begin{tabular}{|l|l|}
\hline \multicolumn{1}{|c|}{ Tipos de modelos } & \multicolumn{1}{c|}{ Conceitos } \\
\hline Modelos prescritivos & $\begin{array}{l}\text { Oferecem orientação sobre os tipos de procedimentos de } \\
\text { GC sem abordar detalhes específicos sobre como esses } \\
\text { procedimentos podem ou devem ser implementados. Na } \\
\text { essência, eles prescrevem maneiras diferentes de se iniciar } \\
\text { atividades de GC. Como tal, esses modelos tendem a ser } \\
\text { baseados em tarefas. }\end{array}$ \\
\hline Modelos descritivos & $\begin{array}{l}\text { Descrevem a GC. Esses modelos identificam os atributos } \\
\text { importantes da GC, devido a sua influência sobre o sucesso } \\
\text { ou o fracasso das iniciativas de GC. }\end{array}$ \\
\hline Modelos híbridos & Combinam os dois modelos. \\
\hline
\end{tabular}

Fonte: adaptado de Rubenstein-Montano et al. (2001), Weber et al. (2002) e Heisig (2009).

Conforme o Instituto de Pesquisa Econômica Aplicada (IPEA, 2005), o conceito de GC para as organizações públicas se fundamenta por meio do agrupamento de 
projetos, de metodologias e de ferramentas. Ainda segundo o IPEA, isso representa a disseminação e a aplicação do conhecimento. Para o Instituto, é importante identificar que o viés público está comprometido com as mais contemporâneas práticas, tais como: transparência; foco nos processos; utilização eficaz das informações e dos conhecimentos; boas práticas de gestão; visão integradora; uso das Tecnologias de Informação e Comunicação (TIC); e foco das necessidades dos cidadãos.

Surge diante dos aspectos apresentados a GC na administração pública, que vai além do que se possa compreender como uma simples ferramenta ou sistema. Do seu viés público, pode-se perceber que a mesma está ligada aos princípios identificados no serviço público, ou seja, à eficiência, à qualidade, à efetividade social, além dos Princípios Constitucionais da legalidade, da impessoalidade, da moralidade, da publicidade e da eficiência (BATISTA, 2012).

Diante disso, o Quadro 11, a seguir, apresenta o eixo temático referente à administração pública e seus desafios junto da GC.

Quadro 11 - Desafios da GC nos eixos temáticos para o desenvolvimento

\begin{tabular}{|c|c|}
\hline Eixo temático & Desafios da GC \\
\hline $\begin{array}{l}\text { Inserção internacional } \\
\text { soberana }\end{array}$ & $\begin{array}{l}\text { Mobilizar os conhecimentos essenciais para elaborar, implementar e avaliar po- } \\
\text { líticas públicas internas e políticas que envolvem o relacionamento com outros } \\
\text { países e povos coerentes com o objetivo de conquistar uma inserção interna- } \\
\text { cional soberana. }\end{array}$ \\
\hline $\begin{array}{l}\text { Macroeconomia para o } \\
\text { desenvolvimento }\end{array}$ & $\begin{array}{l}\text { Mobilizar os conhecimentos essenciais para manejar políticas públicas de for- } \\
\text { ma a articular os diversos atores sociais em torno de um projeto de desenvolvi- } \\
\text { mento nacional sustentável e incluso. }\end{array}$ \\
\hline $\begin{array}{l}\text { Fortalecimento do Es- } \\
\text { tado, das instituições e } \\
\text { da democracia }\end{array}$ & $\begin{array}{l}\text { Mobilizar os conhecimentos essenciais para definir arranjos institucionais mais } \\
\text { adequados para conjugar Estado, mercado e sociedade em torno de um mode- } \\
\text { lo de desenvolvimento sustentável e includente. }\end{array}$ \\
\hline $\begin{array}{l}\text { Estrutura tecnoprodu- } \\
\text { tiva e regionalmente } \\
\text { articulada }\end{array}$ & $\begin{array}{l}\text { Mobilizar conhecimentos essenciais, isto é criar, compartilhar e aplicar conhe- } \\
\text { cimentos, para elaborar, implementar e avaliar políticas públicas referentes aos } \\
\text { temas de ciência e tecnologia, inovação e competitividade, organização produ- } \\
\text { tiva e economia regional. }\end{array}$ \\
\hline $\begin{array}{l}\text { Infraestrutura econômi- } \\
\text { ca, social e urbana }\end{array}$ & $\begin{array}{l}\text { Mobilizar conhecimentos essenciais para atualizar a matriz energética brasileira } \\
\text { e para expandir adequadamente a infraestrutura econômica e social do país } \\
\text { (transportes, fontes energéticas e telecomunicações e as interconexões exis- } \\
\text { tentes entre tais dimensões). }\end{array}$ \\
\hline $\begin{array}{l}\text { Proteção social, garan- } \\
\text { tia de direitos e gera- } \\
\text { ção de oportunidades }\end{array}$ & $\begin{array}{l}\text { Mobilizar conhecimentos essenciais para - por meio de políticas públicas - garantir } \\
\text { direitos, promover a proteção social e gerar oportunidades de inclusão qualificada } \\
\text { (condição necessária a qualquer projeto nacional de desenvolvimento). }\end{array}$ \\
\hline $\begin{array}{l}\text { Sustentabilidade am- } \\
\text { biental }\end{array}$ & $\begin{array}{l}\text { Mobilizar conhecimentos essenciais para: proteger biomas de alta relevância; } \\
\text { implementar iniciativas estratégicas; assegurar o acesso a água potável e a } \\
\text { condições sanitárias adequadas (ativos fundamentais na concepção de desen- } \\
\text { volvimento); e gerenciar a biodiversidade e a biotecnologia. }\end{array}$ \\
\hline
\end{tabular}

Fonte: adaptado de Batista (2012). 
Assim, constata-se, a partir do quadro anterior, que os desafios da GC encontram-se na mobilização de várias maneiras, mas que, em sua maioria, precisam fazer parte das políticas públicas do Estado. Para que isso seja possível, buscar a estrutura, independente de qual patamar esteja, se destaca como primordial, uma vez que as boas gestões são necessárias tanto quanto o atendimento de qualidade a sociedade.

\section{Conclusão}

A busca pelo atendimento das necessidades da sociedade de forma a lhe proporcionar maior dinâmica e prestatividade parece ser o fator primordial junto aos anseios de uma organização ou de uma instituição que pregue a eficiência e a eficácia como atributos inerentes à funcionalidade administrativa. De muitas formas isso pode vir a ser determinante: quando se identifica os pressupostos contemporâneos e, ainda mais, quando se permite perceber que o setor público está empenhado em vir a ser um desses meios.

Assim, apresenta-se a GC como uma ferramenta e um processo pertinente e importantíssimo. O empenho, constatado junto a fatores como a globalização e o momento econômico-financeiro e social, parece ser indicativo de que, cada vez mais, se proponha encontrar ambientes sustentáveis, com alto padrão de qualidade, que sejam adeptos dos avanços tecnológicos e que se permitam ser fontes de informações, essas cada vez mais rápidas.

Osborne e Gaebler (1994), Nonaka e Takeuchi (1997), Davenport e Prusak (1998) e Terra (2001), alinhados aos pensamentos mais recentes de teóricos como Weber et al. (2002), Abdullah e Date (2009), Heisig (2009), Secchi (2009), Batista (2012), dentre outros, apresentam a GC como um relevante mecanismo de melhoria, em especial, no que tange a tomada de decisão. A isso, outros autores imprimiram uma ideia, correspondente ao que se busca junto ao serviço público, seja por definições, seja por apresentação de modelos, que possa melhorar os ambientes e as instituições, o que parece ser extensivo à funcionalidade do Estado e dos governos como um todo.

A similaridade entre os setores público e privado aparece quando se identifica a importância do capital humano, a necessidade de desenvolvimento do capital social e o dever de se encontrar processos que compartilhem as melhores práticas e os demais atributos de gestão, tais como, produtividade, qualidade de serviços e estrutura administrativa (BRESSER-PEREIRA, 1999b; SECCHI, 2009; ABDULLAH; DATE, 2009). Junte-se a isso a percepção da necessidade de se obter 
o equilíbrio entre o conhecimento e as demais ações, que visam à conversão desses em atributos, como competitividade e inovação (DIXON, 2000; SYED-IKHSAN; ROWLAND, 2004).

A queda de paradigmas - a busca por uma GC que se complemente como processo, mecanismo e ferramenta - é o indicativo de um caminho a ser seguido. As mais variadas mudanças e transformações, aliadas à percepção da construção de formas de gestão, tendem a ser vistas como confirmações de anseios administrativos, o que, para a política, como um todo, aparece no atendimentos à população $\mathrm{e}$ na visualização de demandas sociais.

A GC junto à administração pública contribui na produtividade, no atendimento às necessidades da comunidade e, em especial, no pronto atendimento às pessoas, em que se identifica o relacionamento com os clientes e a melhoria dos trabalhos. A rapidez nas ações desempenhadas apresenta-se, nesse sentido, como um diferencial, mesmo porque, muito mais do que a busca pela lucratividade, percebe-se sua funcionalidade, sua eficiência e sua eficácia.

Portanto, a administração pública brasileira prescinde encontrar a sua capacidade de gerenciamento. Embora existam gargalos importantes ainda a serem sanados, são evidentes o eixo temático e os modelos de gestão. É imprescindível o atendimento aos cidadãos aliado à capacidade de eficiência, de eficácia e, especialmente, de respeito à transparência no setor público, o que, de maneira responsável, se justifica quando se procura entender a relevância da gestão pública relacionada à sociedade. 


\title{
Knowledge management in the public sector: its concepts, models and tools
}

\begin{abstract}
The objective of this work is the search for, conceptualize and point out the best practices of Knowledge Management in the public sector. For this, it brings the approach of authors such as Nonaka and Takeuchi (1997), Davenport and Prusak (1998), Dixon (2000), among others. And this is justified by the importance of Knowledge Management, which is seen as a procedural form, appears attentive to the support of institutional and organizational needs, these formalized as modes of management. It is a bibliographical research and ends from a preliminary analysis identifying that, the Brazilian public administration, does not find the means to reach a capacity more oriented to the managerial and productive approach, in an inclusive and concomitant way.
\end{abstract}

Keywords: Knowledge. Management. Public sector.

\section{Gestión del conocimiento en el sector público: sus conceptos, modelos y herramientas}

\section{Resumen}

El objetivo de este trabajo es la búsqueda de, conceptualizar y señalar las mejores prácticas de gestión del conocimiento con el sector público. Para ello, se aporta el enfoque de autores como Nonaka y Takeuchi (1997), Davenport y Prusak (1998), Dixon (2000), entre otros. Y esto se justifica por la importancia de la gestión del conocimiento, que se ve como una forma de procedimiento, parece atento con el apoyo de las necesidades institucionales y de organización, tales como los modos de gestión formalizados. Se trata de una búsqueda en la literatura y termina a partir de un análisis preliminar identificó que el gobierno de Brasil, prescinde de encontrar maneras de lograr una capacidad más específica para la gestión y enfoque productivo, incluyente y al mismo tiempo.

Palabras clave: Gestión. Conocimiento. Sector público. 


\section{Referências}

ABDULLAH; DATE, H. Public sector knowledge management: A generic framework. Public sector management review, Institut Tadbiran Awan Negara, v. 3, n. 1, p. 1-24, jan./jun. 2009. Disponível em: <http://apps.intan.my/psimr/vol3no1/1\%20Public\%20Sector\%20Knowledge\%20 Management.pdf>. Acesso em: 10 abr. 2016.

ALVARENGA NETO, R. C. D. de; VIEIRA, J. L. G. V. Building a knowledge management (KM) model at Brazil's Embrapa (Brazilian Agricultural Research Corporation): towards a knowledge-based view of organizations. Electronic Journal of Knowledge management, EJKM, v. 9, n. 2, p. 7-37, 2011.

AMAYAH, A. T. Determinants of knowledge sharing in a public sector organization. Journal of Knowledge Management, Rochester (USA), v. 17, n. 3, p. 454-471, 2013.

APO - ASIAN PRODUCTIVITY ORGANIZATION. Knowledge management: facilitator's guide. 2009. Disponível em: <http://www.apo-tokyo.org/00e-books/IS-39_APO-KM-FG.htm>. Acesso em: 19 abr. 2016.

BARACCHINI, S. A. A inovação presente na administração pública brasileira. Revista de Administração de Empresas, São Paulo, v. 42, p. 104-109, jun. 2002.

BARBOSA, J. G. P. et al. A proposed architecture for implementing a knowledge management system in the Brazilian National Cancer Institute. Brazilian administration Review, Rio de Janeiro, v. 6, n. 3, p. 247-262, jul./set. 2009. Disponível em:<http://www.anpad.org.br/periodicos/ arq_pdf/a_888.pdf>. Acessado em: 18 maio 2016.

BATISTA, F. F. Modelo de gestão do conhecimento para a administração pública brasileira: como implementar a gestão do conhecimento para produzir resultados em benefício do cidadão. Brasília: IPEA, 2012.

BATISTA, F. F.; ROSENBERG, G.; OHAYON, P. Gestão do conhecimento em organizações públicas de saúde no Brasil: diagnóstico de práticas. Brasília: RSP, 2002.

BORGES JÚNIOR, C. A. et al. Avaliação da melhoria de performance decorrente da implantação da manufatura enxuta na planta s-10 da General Motors do Brasil. In: ENCONTRO NACIONAL DE ENGENHARIA DE PRODUÇÃO, 24., 2004. Florianópolis. Anais... Florianópolis: ABEPRO (UFSC), 2004. p. 1-7.

BRASIL. Constituição da República Federativa do Brasil. Brasília: Senado, 1988.

BRESSER-PEREIRA, L. C. B. Da administração pública burocrática à gerencial. Revista do Serviço Público, Local de publicação, v. 47, n. 1, p. 1-28, jan./abr. 1996.

. Sociedade Civil: sua democratização para a reforma do Estado. In: BRESSER-PEREIRA, L. C. B; WILHEIM, J.; SOLA, L. (Org.). Sociedade e Estado em transformação. São Paulo: UNESP/ENAP, 1999a. p. 67-116.

. Reflexões sobre a reforma gerencial brasileira de 1995. Revista do Serviço Público, Brasília, v. 50, n. 4, p. 5-30, 1999b.

BUKOWITZ, W. R.; WILLIAMS, R. L. Manual de Gestão do Conhecimento: ferramentas e técnicas que criam valor para a empresa. Porto Alegre: Bookman, 2002.

CARVALHO, F. Gestão do Conhecimento. São Paulo: Pearson, 2012. 
CARVALHO, R. B. Tecnologia da informação aplicada à gestão do conhecimento. Belo Horizonte: ComArte, 2003.

CASTRO, G. Proposta de um instrumento para diagnóstico de gestão do conhecimento em bibliotecas universitárias. In: CONGRESSO BRASILEIRO DE GESTÃO DO CONHECIMENTO, 4., 2005, São Paulo. Anais... São Paulo: SBGC, 2005. p. 27-47.

CLAD - CENTRO LATINO-AMERICANO DE ADMINISTRAÇÃO PARA O DESENVOLVIMENTO. Uma nova gestão pública para a América Latina. Revista do Serviço Público, Brasília, a. 50, n. 1, p. 121-144, jan./mar. 1998.

CHOO, C. W. A organização do conhecimento: como as organizações usam a informação para criar significado, construir conhecimento e tomar decisões. São Paulo: Senac, 2003.

CONG, X.; PANDYA, K. V. Issues of knowledge management in the public sector. Electronic Journal of Knowledge Management, Sonning Common (UK), v. 1, n. 2, p. 25-33, 2003.

DAVENPORT, T. H.; PRUSAK, L. Conhecimento empresarial. Rio de Janeiro: Campus, 1998.

DI PIETRO, M. S. Z. Direito administrativo. 23. ed. São Paulo: Atlas, 2010.

DIXON, N. M. Common Knowledge: how companies thrive by sharing what the know. Boston: Harvard Business School Press, 2000.

DRUCKER, P. F. Administrando em tempos de grandes mudanças. São Paulo: Pioneira, 1999.

FAORO, R. R.; OLIVEIRA, M. Compartilhamento do conhecimento intraorganizacional e interorganizacional: empresas do setor de fruticultura. Perspectiva em Gestão \& Conhecimento, Universidade Federal da Paraíba, v. 4, n. 1, p. 98-18, 2014.

FÁTIMA, A. C. de; NASTASI JUNIOR, E.; LIMA JUNIOR, F. R. Uma ferramenta para avaliação do nível de maturidade da gestão do conhecimento organizacional. Revista Eletrônica Gestão \& Saúde, Brasília, v. 6, n. 2, p. 873-890, abr. 2015. Disponível em: <http://gestaoesaude.bce.unb.br/ index.php/gestaoesaude/article/view/1265/pdf>. Acesso em: 12 jan. 2017.

FRESNEDA, P. S. V.; GONÇALVES, S. M. G. A experiência brasileira na formulação de uma proposta de gestão do conhecimento para a administração pública federal. Brasília: Câmara dos Deputados, 2007. Disponível em: <http://pt.scribd.com/doc/12868587/Fresneda-Goncalves-2007-Proposta-de-Politica-de-GCna-Adm-Publica-Federal>. Acesso em: 11 jan. 2017.

FIGUEIREDO, S. P. Gestão do Conhecimento: estratégias competitivas para a criação e mobilização do conhecimento na empresa. São Paulo: Qualitymark, 2005.

FIRESTONE, J.; MCELROY, M. Doing Knowledge Management. The Learning Organization, Emerald Insight (UK), v. 12, n. 2, p. 189-212, abr. 2005.

FONSECA, A. F. Organizational Knowledge Assessment Methodology. Washington: World Bank, 2006.

FRANCO, D. H.; RODRIGUES, E. A.; CAZELA, M. M. Tecnologias e ferramentas de gestão. Campinas: Alínea, 2012.

GARVIN. D. A. Construindo a organização que aprende. Harvard Business Review, Rio de Janeiro, v. 1, a. 1, p. 27-49, 2000.

GOLDMAN, F. L. Podemos ainda aprender com Nonaka e Takeuchi? In: KM BRASIL Gramado, 7, 2010. Anais... Gramado: KM BRASIL, 2010. p. 1-26. 
GUBERMAN, G. A dinâmica da lentidão: organizações públicas como inibidoras do desenvolvimento. Rio de Janeiro: FGV/EBAPE, 2010.

HANLEY, S.; MALAFSKY, G. A guide for measuring the value of KM investments. In: HOLSAPPLE, C. W. Handbook on Knowledge Management. Heidelberg, primavera 2004. p. 367-390.

HEISIG, P. Harmonisation of knowledege management - comparing $160 \mathrm{KM}$ frameworks around the globe. Journal of Knowledge Management, Emerald (UK), v. 13, n. 4, p. 4-31, 2009.

HOLANDA, L. M. C.; DIHL, W.; FRANCISCO, A. C. O perfil da produção científica em gestão do conhecimento: análise dos artigos do Simpósio de Excelência em Gestão e Tecnologia (SEGET). In: SIMPÓSIO DE EXCELÊNCIA EM GESTÃO E TECNOLOGIA, 6., 2009, Resende. Anais... Resende: Associação Educacional Dom Bosco Resende, 2009. p. 1-20.

IPEA - INSTITUTO DE PESQUISA ECONÔMICA APLICADA. Gestão do conhecimento na administração pública. Brasília: IPEA, 2005. (Texto para discussão).

JARBOE, K.; ALLIANCE, A. Knowledge management as an economic development strategy. Chicago (EUA): Economic Development Administration, 2001. Disponível em: <http://www.athenaalliance.org/apapers/eda.html>. Acesso em: 23 maio 2016.

JENNEX, M. E.; OLFMAN, L.; ADDO, T. B. A. The Need for an Organizational Knowledge Management Strategy, Proceedings of the Hawaii. In: INTERNATIONAL CONFERENCE ON SYSTEM SCIENCES, 36., 2002, Havaí. Anais... Havaí: IEEE, 2002. p. 7-26.

KAPLAN, R. S.; NORTON, D. P. Medindo a prontidão estratégica de ativos intangíveis. Harvard Business Review, Rio de Janeiro, v. 1, p. 38-48, fev. 2004.

LUKÁCS, E. The economic role of SMES in the world economy, especially in Europe. European Integration Studies, Bonn, v. 4, n. 1, p. 3-12. 2005.

MACHLUP, F. Semantic Quirks in Studies of Information. Nova York: John Wiley \& Sons. 2003.

MARCANTE, C. et al. A gestão do conhecimento como recurso estratégico: para adoção de práticas empreendedoras. In: CONGRESSO DE PESQUISA E EXTENSÃO DA FACULDADE DA SERRA GAÚCHA, 3. 2015, Caxias do Sul. Anais... Caxias do Sul: FSG, 2015. p. 421-440.

MODESTO, P. E. G. Reforma administrativa e marco legal das organizações sociais no Brasil: as dúvidas dos juristas sobre o modelo das organizações sociais. Revista do Serviço Público, Brasília, a. 48, n. 2, p. 27-57, maio/ago. 1997.

MONAVVARIAN, A.; KASAEI, M. A KM model for public administration: the case of Labour Ministry. The Journal of Information and Knowledge Management Systems, Emerald (UK), v. 37, n. 3, p. 348-367, 2007.

NATIONAL INSTITUTE OF STANDARDS AND TECHNOLOGY. Baldrige National Quality Program's Criteria for Performance Excellence. Gaithersburg, 2006.

NONAKA, I.; TAKEUCHI, H., The knowledge-creating company: how Japanese companies create the dynamics of innovation. New York: Oxford University Press, 1997. (Edição inglesa).

. Criação de conhecimento na empresa: como as empresas japonesas geram a dinâmica da inovação. 20. ed. Rio de Janeiro: Elsevier, 1997. (Edição portuguesa).

. A empresa do conhecimento. In: TAKEUCHI, H.; NONAKA, I. Gestão do conhecimento.

Porto Alegre: Bookman, 2008. p. 320.

Teoria e Evidência Econômica - Ano 23, n. 48, p. 172-203, jan./jun. 2017 
OLIVEIRA, M.; CALDEIRA, M.; ROMÃO, M. Knowledge management implementation: an evolutionary process in organizations. Knowledge and Process Management, John Wiley \& Sons, v. 19 , n. 1 , p. $17-26.2014$.

ORR, E.; PERSSON, M. Performance indicator for measuring performance of activities In: Knowledge management projects. Master Thesis. University of Gothenburg, 2003. Disponível em: <https://gupea.ubu.gu.se/bisstream/2077/1214/1/Nr6_EO\%2CMP.pdf>. Acesso em: 16 jan. 2017.

OSBORNE, D.; GAEBLER, T. Reinventando o governo: como o espírito empreendedor está transformando o setor público. Brasília: MH, 1994.

DE PAULA, A. P. P. Por uma nova gestão pública: limites e potencialidades da experiência contemporânea. Rio de Janeiro: FGV, 2005.

PANAHI, S.; WATSON, J.; PARTRIDGE, H. Towards tacit knowledge sharing over social web tools. Journal of Knowledge Management, Emerald (UK), v. 17, n. 3, p. 379-397. 2013.

POKHAREL, M. P.; CHOI, S. A. Exploring the relationships between the learning organization and organizational performance. Management Research Review, Emerald (UK), v. 38, n. 2, p. 126-148. 2015.

PROBST, G.; RAUB, S.; ROMHARDT, K. Gestão do Conhecimento: os elementos construtivos do sucesso. Porto Alegre: Bookman, 2002.

RAGAB, M. A. F.; ARISHA, A. Knowledge management and measurement: a critical review. Journal of Knowledge Management, Emerald (UK), v. 17, n. 6, p. 873-901. 2013.

RUBENSTEIN-MONTANO, B. et al. A systems thinking framework for knowledge management. Decision Support Systems, Elsevier, v. 31, n. 1, p. 5-16. 2001.

SALAVATI, A.; SHAFEI, R.; SHAGHAYEGH, E. A model for adoption of knowledge management in Iranian public organizations. European Journal of Social Sciences, Victoria (mahé), v. 17, n. 1, p. 22-45, 2010.

SANDHU, M. S.; JAIN, K. K.; AHMAD, I. U. K. Knowledge sharing among public sector employees: evidence from Malaysia. International Journal of Public Sector Management, Chicago (USA), v. 24, n. 3, p. 206-226, 2009. Disponível em: <http://www.emeraldinsight.com/journal/ ijpsm>. Acesso em: 16 jan. 2017.

SECCHI, L. Modelos organizacionais e reformas da administração pública. Revista de Administração Pública, Rio de Janeiro, v. 43, n. 2, p. 347-69, mar./abr. 2009.

SYED-IKHSAN, S. O. S; ROWLAND, F. Knowledge management in an organization public: a study on the relationship between organizational elements and the performance of knowledge transfer. Journal Knowledge Management, Emerald (UK), v. 8, n. 2. p. 95-111. 2004.

TEECE, D. J.; PISANO, G.; SHUEN, A. Dynamic capabilities and strategic management. Strategic Management Journal, John Wiley \& Sons, v. 18, n. 7, p. 509-533, 1998.

TERRA, J. C. C. Gestão do conhecimento: o grande desafio empresarial. São Paulo: Negócio, 2001.

. Dimensões da gestão da inovação: uma abordagem para a transformação organizacional. Rio de Janeiro: Elsevier, 2012. 
WEBER, F. et al. Standardization in knowledge management - towards a common KM framework in Europe. In: UNICOM SEMINAR, 2002, Londres. Anais... Londres: UNICON, 2002. p. 37-65.

WEE, J. C. N.; CHUA, A. Y. K. The peculiarities of knowledge management processes in SMEs: the case of Singapore. Journal of Knowledge Management, Emerald (UK), v. 17, n. 6, p. 958-972. 2013.

WIIG, K. M. Introducing Knowledge management into the enterprise. In: LIEBOWITZ, J. (Ed.). Knowledge management handbook. John Wiley \& Sons: CRC, 2000.

Knowledge management in public administration. Journal of Knowledge Management, Emerald (UK), v. 6, n. 3, p. 224-239, 2002.

WOODFORD, C. Public sector knowledge management: taking responsibility. A report prepared by Adept KM for a Federal Government Agency, 2003. 